\title{
Procesos de comunicación para la paz
}

\author{
Alejandra Toro Calonje** \\ Recibido: 2019-06-14 • Enviado a pares: 2019-06-28 \\ Aprobado por pares: 2019-07-28 • Aceptado: 2019-09-20 \\ https://doi.org/10.22395/angr.v18n36a7
}

\begin{abstract}
Resumen
La reflexión que aquí se presenta emana de dos investigaciones realizadas con mujeres víctimas de la violencia política en Colombia, ubicadas ambas en el campo de la Comunicación Social. Metodológicamente, se sometieron a prueba hipótesis de la teoría de la paz imperfecta y de la investigación para la paz con base en ejercicios de transcodificación artística a través de procesos concebidos desde la Comunicación Social, adelantados por víctimas del conflicto y cuya finalidad era producir una obra artística propia a partir de otra pre-existente. A partir de relatos de sus experiencias, las participantes, confrontadas a obras artísticas, transformaron la obra ajena de la cual se inspiraron, en otra de autoría propia. Dicha experiencia, según estas teorías, propicia el duelo y la resiliencia de las víctimas a través del empoderamiento personal, fundamentales para las paces. El trasfondo social de estas experiencias ha sido el postconflicto tras los acuerdos de paz entre las FARC y el gobierno colombiano. El primer proceso se adelantó con mujeres afrodescendientes desplazadas del Pacífico a Cali; el segundo con estudiantes socialmente desfavorecidas por la violencia en sus regiones de origen. Estos ejercicios desembocaron en un cambio en la percepción de las mujeres sobre su experiencia personal violentada y como consecuencia, en su capacidad para hacer las paces.
\end{abstract}

Palabras clave: paz imperfecta; arte; transcripción; conflicto social; postconflicto; consolidación de la paz; cuerpo; biopolítica; noviolencia.

\footnotetext{
Artículo resultado de la investigación Organizaciones y movilización social: impacto de los procesos de comunicación (un ejercicio de paz imperfecta), derivada de La presencia de la ausencia. Cuerpo y arte en la construcción de paz: la danza como forma de revisibilización de víctimas de desaparición en el conflicto armado colombiano, investigación con la cual su autor obtuvo el grado de doctorado, Colombia * Profesora de la Escuela de Comunicación Social, Facultad de Artes Integradas, Universidad del Valle, Cali, Colombia.Correo electrónico: alejandra.toro.calonjea@correounivalle.edu.co. Orcid: https://orcid.org/0000-0003-0136-5637
} 


\title{
Communication Processes for Peace
}

\begin{abstract}
The reflection presented here emanates from two investigations carried out with women victims of political violence in Colombia, both located in the field of Social Communication. Methodologically, hypothesis of imperfect peace theory and peace research were tested based on artistic transcoding exercises through processes conceived from a Social Communication perception and performed by victims of the conflict. Its purpose was to produce a personal artistic work from pre-existing ones. Taking as a starting point the stories of their experiences, participants confronted artistic pieces and transformed thesa work that inspired them, to create another one of their own. This experience, according to these theories, fosters the mourning and resilience of victims through personal empowerment, fundamental to peace. The social background of these experiences has been the post-conflict following the peace agreements between the FARC and the government. The first process was advanced with Afro-descendant women displaced from the Pacific to Cali; the second with students socially disadvantaged by violence in their home regions. These exercises resulted in a change in women's perception of their violent personal experience and, as a consequence, in their ability to make peace.

Keywords: imperfect peace; art; transcription; social conflict; post-conflict; peacebuilding; body; biopolitics; nonviolence.
\end{abstract}

\section{Processos de comunicação para a paz}

\section{Resumo}

Esta reflexão é fruto de duas pesquisas realizadas com mulheres vítimas da violência política na Colômbia, localizadas no campo da Comunicação Social. Como metodologia, foram submetidas à prova hipóteses da teoria da paz imperfeita e da pesquisa para a paz com base em exercícios de transcodificação artística por meio de processos concebidos a partir da Comunicação Social, realizados por vítimas do conflito e cuja finalidade era produzir uma obra artística própria com base em outra preexistente. Segundo relatos de suas experiências, as participantes, confrontadas a obras artísticas, transformaram a obra alheia na qual se inspiraram em outra de autoria própria. Essa experiência, conforme essas teorias, propicia o luto e a resiliência das vítimas por meio do empoderamento pessoal, fundamentais para a paz. O fundo social dessas experiências tem sido o pós-conflito após os acordos de paz entre as Forças Armadas Revolucionárias da Colômbia e o governo colombiano. O primeiro processo foi realizado com mulheres afrodescendentes deslocadas do Pacífico a Cali; o segundo com estudantes socialmente desfavorecidas pela violência em suas regiões de origem. Esses exercícios levaram a uma mudança na percepção das mulheres sobre sua experiência pessoal violentada e, como consequência, em sua capacidade para fazer as pazes.

Palavras-chave: paz imperfeita; arte; transcrição; conflito social; pós-conflito; consolidação da paz; corpo; biopolítica; não violência. 


\section{Introducción}

El objeto de este trabajo es reflexionar sobre los alcances conceptuales de dos procesos concebidos y orientados desde la Comunicación Social que incidieron en los miembros de una organización social. Ambos procesos utilizaron el arte como instrumento y perseguían la construcción de una nueva memoria con base en la idea de Haye et al. (2018) según la cual "la memoria no solo está organizada y distribuida socialmente, sino que está mediada por sistemas semióticos, formas culturales, géneros de comunicación y enunciados" (p. 24). El arte es, sin duda, un sistema semiótico particular. La finalidad de esta experiencia ha sido propiciar un cambio de percepción en las personas que participaron en ella, en el marco de una sociedad como la colombiana, en pleno proceso de construcción de paz. Las reflexiones apuntan a configurar un cuerpo de conceptos con los cuales desde la Comunicación Social se podrían producir movilizaciones ${ }^{1}$ en la consciencia de quienes han sido víctimas de la violencia política, según procesos que hemos llamado "transcodificación artística".

La experiencia ha sido pensada como un proceso de comunicación social. Los mecanismos operativos aplicados, las relaciones entre los participantes, las herramientas utilizadas, los objetivos, las valoraciones de los hechos, todo se concibió bajo la idea de un comunicador social-mediador, según lo entiende Jesús MartínBarbero (2011), alguien que asume las "asimetrías" sociales y busca intervenir en la construcción de la democracia.

El texto apela a conceptos provenientes de la paz imperfecta y de la investigación para la paz que consideran como víctimas de la violencia política, no solo a los muertos y sus familiares/deudos, desaparecidos y desplazados, sino también a quienes han sufrido los efectos de la desigualdad por los que la sociedad en que viven entró en conflicto. La extensión a la sociedad del proceso de comunicación se hace con el fin de lograr, según Franco y López (2011), "la prosperidad material, la justicia social, la libertad para todos y el gobierno de la mayoría" (p. 174).

La movilización a la que aludimos, puesto que está pensada en el contexto político colombiano actual, busca encontrar vías que conduzcan a la paz. En síntesis, queremos mostrar y analizar experiencias en las que la Comunicación -a través de prácticas artísticas-media en organizaciones sociales para que sus miembros se movilicen hacia la paz en el marco del conflicto actual colombiano.

Se busca - de una parte- demostrar hipótesis de la teoría de la paz imperfecta y de la investigación para la paz, de acuerdo con las cuales las víctimas de violencia

Se entiende la expresión "movilización social" como el proceso mediante el cual individuos determinados transforman positivamente la visión que tienen de sí mismos y su percepción de los problemas en que están inmersos. No se debe confundir "movilización" con "movilidad" (que refiere a desplazamiento físico; la movilización, en cambio, es de la consciencia). 
política se encuentran preparadas para la paz si media un proceso creativo que conduzca al empoderamiento personal y, ulteriormente, se alcance y les permita realizar el duelo. De otra parte, crear las condiciones -así sea en una escala modesta- para que el proceso de paz se consolide ${ }^{2}$. El problema también admite preguntarse sobre el interés de trabajar con estas personas, vulneradas por la sociedad y desplazadas por su condición en la periferia social.

Gabriel Pérez (2009) establece la relación entre la ética y la comunicación en la perspectiva del restablecimiento de los derechos humanos. Distingue tres momentos en los que la humanidad ha tomado conciencia sobre ellos: el primero corresponde a los derechos civiles y políticos; el segundo se refiere a los derechos económicos, sociales y culturales; el tercero está centrado en el concepto de solidaridad, que incluye el derecho a la paz y al desarrollo sostenible. Rescatamos sobre todo el último, "en el sentido de la igualdad de todas las personas como integrantes de la familia humana, más allá de las fronteras políticas nacionales" (Pérez, 2009, p. 53, acento nuestro). Este último eslabón es el que permite, en términos de Pérez, restablecer la dignidad humana, cuyo reconocimiento es el catalizador del restablecimiento de todos los demás derechos. Más importante aún: los procesos que incluyen a todas las personas integrantes de la familia humana facilitan el acceso a la toma de decisiones democráticas, volviéndolas visibles en el espectro social. Así, estos ejercicios con personas marginadas permiten

[... la posibilidad real y efectivamente reconocida de todos los integrantes de la sociedad de tomar parte activa, como interlocutores, en las decisiones que afectan la búsqueda, la determinación de los contenidos y la realización de la vida buena para todos. (Pérez, 2009, p. 53)

\section{Objetivos}

El objetivo general de este artículo es mostrar cómo la transcodificación, inscrita en procesos de comunicación y con el arte como recurso, puede suscitar procesos de duelo y empoderamiento en víctimas de un conflicto político que conduzcan a la consciencia de su condición y a su capacidad de hacer las paces.

La pregunta central de este artículo es: ¿De qué manera el arte, a través de procesos de transcodificación, interviene en los procesos de duelo de víctimas de un conflicto político para acercarlas a la reconciliación social? Los objetivos específicos son: proponer nuevas formas de acercamiento al conflicto; propiciar procesos de resiliencia y empoderamiento entre las víctimas; producir obras artísticas a partir de las voces de las víctimas.

El 29 de agosto de 2019, disidencias de las FARC anunciaron su reactivación. Numerosos analistas ya lo predecían. Así, Lemaitre y Restrepo (2019) afirmaron que la ausencia del Estado en los territorios que antes estaban bajo control de las FARC podía hacerlos "presa de la barbarie" (p. 3). Creemos entonces que es en estas circunstancias cuando procesos como los emprendidos en estos proyectos de investigación adquieren mayor relevancia. 


\section{Objeto de estudio}

El objeto de estudio de este artículo es la confluencia del cuerpo, la transcodificación y el arte como elementos que conducen a la reconciliación de las víctimas y, por tanto, a la construcción de la paz.

\section{Aspectos teóricos}

Este apartado subraya los aspectos más relevantes de la teoría de la paz imperfecta y de la investigación para la paz, y añade otras dimensiones conceptuales que, aunque no pertenecen intrínsecamente a las teorías anteriores, convergen en el desarrollo de este trabajo.

\section{La paz imperfecta}

La teoría de la paz imperfecta es una derivación de la investigación para la paz. Esta última aparece tras la Segunda Guerra Mundial como consecuencia de la convicción cada vez más fuerte de que los desarrollos nucleares tenían la capacidad de destruir a la humanidad entera. Nagazaki e Hiroshima ofrecían en pequeña escala la prueba más fehaciente. La paz se erigió entonces como objetivo de primer orden si se quería evitar la destrucción total de la humanidad. La ausencia de guerra se consideraba paz negativa. Aunque no bastaba simplemente con la no existencia de la guerra: hacia mitad del siglo pasado, el tema de la paz se empezó a pensar desde perspectivas multidisciplinarias (Harto de Vera, 2016). Johan Galtung (1985), uno de los principales investigadores en este campo, consideró hacia los años sesenta que era insuficiente hablar de paz negativa. La paz no puede ser solamente la ausencia de la guerra sino el resultado de resolver las causas estructurales que han dado origen al conflicto. La paz positiva, como se le comienza a llamar, se debe formular en términos de justicia social. Galtung reconvirtió los estudios sobre la paz en una disciplina que incluía la justicia social y el respeto por los derechos humanos. La paz positiva supone un conjunto de circunstancias y medidas que traduce el concepto complejo de justicia social: libertades, garantías, equidad, acceso a la educación y a la salud, oportunidades, seguridad, derechos humanos.

A comienzos del siglo actual, Francisco Muñoz del Instituto de la Paz y los Conflictos de la Universidad de Granada, propuso el concepto de paz imperfecta como desarrollo a partir de la investigación para la paz. La diferencia introducida por Muñoz radica en desplazar el foco de atención de estos estudios: del énfasis en la violencia se pasa al énfasis en la paz. Para Muñoz, Herrera, Molina y Sánchez (2005), las acciones de paz se deben aplicar "a pesar de que estén en contextos en los que existen los conflictos y la violencia" (p. 29). 
La paz imperfecta no es absoluta; reconoce la existencia del conflicto y no espera suprimirlo pues se alimenta de su contradicción. Nunca se perfecciona porque algo perfecto agota su capacidad de evolución; está, por el contrario, en permanente mutación, estimulada por el conflicto. Es una paz que nunca se termina de construir por estar siempre sujeta a interrogaciones desde diversos campos del conocimiento. Una paz así concebida vive en las diferencias y desde allí crea experiencias comunes para que los individuos de una sociedad, inmersos en el antagonismo, se puedan relacionar sin violencia. Es un principio democrático: no se espera la desaparición del contrario, sino que lo requiere y acepta. La paz imperfecta celebra los encuentros con el contrario y se nutre de ellos.

El conflicto es la condición misma de la sociedad. Se podría creer que su eliminación traería la paz automáticamente, o que la búsqueda de la paz se favorecería con su supresión. Estanislao Zuleta señala la importancia de la contradicción en el funcionamiento de la sociedad y juzga ingenuo el pensamiento que sueña con una sociedad ajena al conflicto.

Deseamos mal. En lugar de desear una relación humana, inquietante, compleja y perdible, que estimule nuestra capacidad de luchar y nos obligue a cambiar, deseamos un idilio sin sombras y sin peligros, un nido de amor y por lo tanto en última instancia un retorno al huevo. En vez de desear una sociedad en la que sea realizable y necesario trabajar arduamente para hacer efectivas nuestras posibilidades, deseamos un mundo de satisfacción, una monstruosa sala cuna de abundancia pasivamente recibida. Lo difícil, pero también lo esencial es valorar positivamente el respeto y la diferencia, no como un mal menor y un hecho inevitable, sino como lo que enriquece la vida e impulsa la creación y el pensamiento. (Zuleta, 2000)

Muñoz y Molina (2010) afirman que los conflictos son una "circunstancia inherente al ser humano, con la que se abren enormes capacidades creativas, generadoras de bienestar, sin que ello suponga negar sus derivaciones violentas" (p. 2). Y para Francisco Muñoz (2001), el conflicto forma parte del universo, de todas las realidades que lo componen y de las relaciones entre ellas.

Componentes importantes de la teoría de la paz imperfecta serían los siguientes:

\section{Resiliencia}

La resiliencia es la capacidad de los seres humanos para sobreponerse a la adversidad y construir sobre ella. Se la entiende como un proceso dinámico que tiene como resultado la adaptación positiva, aún en contextos de gran adversidad. La resiliencia es resistir y reconstruirse (Manciaux en Cyrulnik et al., 2006, p. 167).

Boris Cyrulnik desarrolla este concepto, inicialmente lo aplica a niños. "La resiliencia es una actitud filosófica con respecto a las desgracias, la victimización, y 
probablemente se trata [...] de una actitud de combate" (Cyrulnik et al., 2006, p. 3). Por extensión, ser resiliente implica la acción de resurgir, la posibilidad que tienen los seres humanos de recuperarse después de un shock, romper la parálisis ocasionada por la violencia y sobreponerse al dolor, resistir, adaptarse, evolucionar y recuperarse después de una pérdida mayor. El cuerpo puede volver a ser lo que fue. La resiliencia no es solamente la capacidad para sobreponerse a acontecimientos traumáticos; es sobre todo la aptitud para salir fortalecido de ellos. Implica la posibilidad de readaptación del individuo en la vida cotidiana, después del desgarro provocado por la pérdida. El hombre, incluso en las condiciones más extremas de deshumanización y sufrimiento, puede encontrar una razón para vivir. "Toda situación extrema en tanto que proceso de destrucción de la vida, encierra en forma paradójica un potencial de vida" (Cyrulnik et al., 2006, p. 62). Ese potencial de vida es lo que permite el reconocimiento de sus propios sueños y de la posibilidad de realizarlos.

Para provocar una ruptura con el hecho doloroso (para ser resiliente), el sujeto se debe negar a aceptar lo inaceptable (Colmenares, en Cyrulnik et al., 2006). El acento recae pues en el sujeto, agente y pilar de los procesos de reconstrucción que tiene responsabilidades frente a sí mismo. "El acto resiliente es un acto libre que responsabiliza al sujeto de sus decisiones" (Balegno, en Cyrulnik et al., 2006, p. 236).

La resiliencia, considerada desde la perspectiva de sujeto, desborda el infortunio y ofrece apoyo a la persona víctima para mantener el reconocimiento de su identidad en tanto que referencia de derechos, deberes, saberes, para favorecer la toma de consciencia de valores de existencia como criterio de evaluación de la realidad que vive. (Colmenares, en Cyrulnik et al., 2006, p. 85)

Sin la resiliencia no hay duelo, sin duelo no hay paz. La resiliencia tiene todo que ver con la recuperación de la esperanza.

\section{Los conflictos}

Uno de los aspectos fundamentales de los estudios para la paz es el análisis de los conflictos. Estos se entienden como una "circunstancia inherente al ser humano, con la que se abren enormes capacidades creativas, generadoras de bienestar, sin que ello suponga negar sus derivaciones violentas" (Muñoz y Molina, 2010, p. 2).

Decía Francisco Muñoz:

El conflicto forma parte del universo, de todas las realidades que lo componen y de las relaciones que se establecen entre ellas [...]. Casi nos atreveríamos a decir que el "conflicto" es una característica de los seres vivos que en su intento de perpetuarse como individuos frente a la muerte y como especie frente a la extinción pretenden utilizar en su beneficio los recursos y la energía disponible en su entorno. (Muñoz, 2001) 
La teoría de los conflictos es uno de los aportes más valiosos de los estudios sociales para interpretar las relaciones entre las personas, los grupos y la propia especie, ya que a través de ellos es posible comprender las redes de relaciones, el papel de los valores y las ideas, las conductas y comportamientos, la distribución del "poder" y los mecanismos de cambio. El conflicto es, de esta forma, un concepto central para la explicación de la dinámica de las entidades humanas (individuos, grupos, especie) (Muñoz et al., 2005, pp. 55-56).

El conflicto se ha de entender ante todo como una fuente de creatividad. Con Galtung (1985), el interés particular de la investigación para la paz ha sido ver las causas de la violencia y buscar soluciones a la misma, lo cual convierte el conflicto en la base teórica, epistemológica y práctica de la paz y la violencia.

El conflicto y la cooperación son las dos caras de las relaciones humanas. La cooperación entendida como "una acción de dos o más agentes que obran juntos y producen un mismo objetivo, o como ayuda, auxilio o socorro que se presta para el logro de alguna cosa" (Muñoz y Molina, 2010, p. 8). La cooperación es un compromiso altruista y filantrópico. Los humanos somos seres imperfectos, en quienes conviven la cooperación y el egoísmo, el altruismo y la codicia, la paz y la violencia. Sin embargo, los conflictos nos imponen ser cooperativos, dependientes del otro y nos enseñan a ser solidarios. Así, los procesos de adaptación de los homínidos pasaron por la socialización y el reconocimiento del otro, lo cual se tradujo en cooperación y armonía.

\section{Empoderamiento pacifista}

El empoderamiento pacifista hace parte de aquellas interacciones (o mediaciones) que puede generar un sistema basado en la complejidad. Esta praxis se define como:

[...] un reconocimiento de las realidades, prácticas y acciones pacifistas y sus capacidades para actuar y transformar su entorno más o menos cercano; y para impulsar y promover la creación de redes entre todos los actores que de una u otra forma tienen intereses en promocionar la paz. (Muñoz et al., 2005, p. 138)

Se quiere expresar a través de empoderamiento pacifista la capacidad que tienen los seres humanos para tomar en sus propias manos el curso roto de sus vidas y asumir sus circunstancias personales, por más dolorosas que sean. Es un caso típico de resiliencia, gracias a la cual los seres humanos recuperamos cierto estado de equilibrio, perdido por la intervención brutal de una fuerza destructiva. La víctima asume su historia y construye su propio resurgir (social, síquico, moral). El empoderamiento pacifista debe permitir a la víctima la reconstrucción de su visibilidad social, la recuperación de su dignidad, la readquisición de su corporalidad y de su condición extraviada de ser social a través de la activación de sus capacidades creativas. Hablar de capacidades creativas es hablar de capacidades artísticas, con lo cual aludiríamos 
de forma explícita al asunto central del presente artículo: la transformación de la percepción a través del arte.

¿Qué poder tiene la paz para influir en los aspectos personales, políticos, sociales?, se preguntaba Muñoz (2014). La respuesta radica en el empoderamiento pacifista. Este, insistía Muñoz, rompe con la perspectiva bipolar del enemigo. Al reconocer sus capacidades, se habla más bien en términos de "adversario", se le reconoce su dignidad. Es reconocer al otro y escuchar tanto a víctimas como a victimarios. Eso es lo que permite a las primeras hacer las paces con los segundos e iniciar el camino que permita a las víctimas perdonar a sus victimarios. Como lo plantea Jacques Derrida (2012), "al estar ligado a un pasado que de alguna manera persiste, el perdón no puede ser considerado una experiencia equivalente a la de un don, puesto que éste [sic] se otorga más corrientemente en el presente" (p. 10). El perdón es, por ende, una construcción social, no un acto natural.

"La necesidad de empoderarse es la única posibilidad de transformación de una realidad desigual", afirmaba el profesor Muñoz, como la toma de conciencia y actitud de transformación, desde lo individual a lo público,

[...] en un proceso en el que son reconocidos todos los actores, públicos y privados, y sus capacidades para que las acciones de paz se dimensionen el máximo posible en la toma de decisiones implicadas en el bienestar de las sociedades. (Muñoz et al., 2005, p. 10)

\section{La transcodificación artística}

Puesto que la técnica empleada para el desarrollo de los talleres referidos -corazón metodológico de este trabajo- fue la transcodificación artística, conviene definirla más rigurosamente: es el ejercicio de interpretación que realiza un individuo o un grupo de una obra artística al transformarla en otra, igualmente artística, expresada en otro lenguaje semántico. Este concepto nace de una homología del concepto planteado por Roman Jakobson, quien argumentaba que hay una "traducción intersemiótica" cuando ocurre "una interpretación de los signos verbales mediante los signos de un sistema no verbal" (Jakobson, 1984, p. 69), por ejemplo, pintar (signos icónicos) narraciones de acontecimientos violentos de la guerra (signos verbales). Con estos términos podríamos estar hablando de muchas obras: Guernica de Picasso; los cuadros de Botero sobre Abu Ghraib; los cuadros de Goya sobre la guerra española de mayo de 1808; La libertad guiando al pueblo de Eugène Delacroix. En términos globales, transcodificar es pasar de un código a otro, de manera que decir transcodificación artística remite a la idea de que se pasa de un código artístico a otro igualmente artístico. Ejemplo: Proust describió en sus novelas las alegorías de vitrales de diversas iglesias (transmutando así un código icónico en otro verbal, ambos artísticos). Otro: la coreografía de danza 
contemporánea de El Colegio del Cuerpo en Colombia, "Inxilio: Sendero de lágrimas", en la que se pasa de los códigos verbales de las historias de la guerra a los códigos corporales de la danza y la música.

La transcodificación artística es un caso particular de transcodificación, operación que continuamente hacemos todos en todos los campos de la vida en sociedad: como pacientes traducimos para el médico nuestros signos corporales en signos verbales; como transeúntes traducimos los signos viales en actitudes y comportamientos del cuerpo; como críticos de arte transcodificamos obras artísticas en lenguajes verbales o audiovisuales. La escritura transmedia transcodifica un mismo acontecimiento en discursos mediáticos de distinto soporte semántico (icónico, verbal, audiovisual...).

Los casos de transcodificación son infinitos pues el uso de cualquier lenguaje -lo que hacemos sin cesar como seres humanos- conlleva el paso de un código a otro.

\section{El cuerpo}

Si el sustrato común a las dos experiencias investigativas es el arte, hay que precisar que la experiencia de las víctimas al realizar la transcodificación artística se apoya materialmente en sus cuerpos. Sin el cuerpo el arte no existiría, como nada podría existir sin el cuerpo. Las mujeres del Pacífico terminan por danzar sus propios problemas e historias de vida; decir que lo hacen con sus cuerpos es una obviedad pues al hablar de danza necesariamente se habla del cuerpo. En la segunda experiencia, las jóvenes estudiantes se valen de su cuerpo para objetivar sus sentimientos: no otra cosa ocurre cuando una canta, la otra danza, una tercera ejecuta un instrumento, etc. Todo pasa por el cuerpo.

Para Merleau-Ponty (2013), el cuerpo es fundamental en la percepción pues es a través suyo que se establece la relación con el mundo. El mundo es aquello que percibimos, y es el cuerpo el que nos permite el contacto con el mundo, tocar y ser tocados. Le Breton (2010) afirmó que:

El niño debe aprender el mundo para gozar de él. Para el hombre, el único medio de aprender es experimentar el mundo, ser atravesado y alterado por él con conciencia más o menos viva. El cuerpo está mezclado al mundo y el individuo sólo [sic] toma conciencia de él a través de su sentir. (p. 22)

Calero, Rivera y Restrepo (2015) sostuvieron que:

[... la producción social de sentido y la interacción social se materializan en el cuerpo. No es posible conversar, escribir, sembrar, llorar, reír, comer, matar, desplazarse, sin un cuerpo. [...] planteamos que la experiencia social se inicia y se tramita con el cuerpo: es el cuerpo el que chatea, trabaja, ve televisión, baila, cocina, teje, pinta, toma fotografías; es el cuerpo el que utiliza prótesis para intentar decir y hacer algo; [... es el cuerpo el que interactúa con la naturaleza y desde la naturaleza. (p. 14) 
No se puede renunciar al cuerpo. Está allí, junto a su propietario, tercamente, irremisiblemente fiel. A dónde va el uno, el otro le sigue. Es imposible prescindir de él pues es el lugar de origen y de convergencia de todas las actividades de los seres humanos. Sin él, solo hay vacío. El cuerpo lo es todo; es el gran sustrato en que se materializan los propósitos soñados por los seres humanos y el lugar en el cual se experimentan las contradicciones y se viven los desafíos. Leamos la reflexión de Foucault acerca de la imposibilidad de un cuerpo utópico:

[...] apenas abro los ojos ya no puedo escaparme de ese lugar. No es que me tenga clavado en el suelo, porque después de todo, puedo no solo moverme y agitarme, puedo "moverlo" y "agitarlo" [al cuerpo], cambiarlo de lugar. Pero es un hecho: no puedo desplazarme sin él. No puedo dejarlo ahí donde está para irme, yo, a otra parte. Puedo irme lejos, puedo atrincherarme, en la mañana, bajo mis cobijas, hacerme tan pequeño como pueda, puedo dejarme derretir bajo el sol en la playa, siempre estará donde yo estoy. Está aquí, irremediablemente, nunca en otra parte. Mi cuerpo es lo contrario de una utopía, lo que no existe nunca bajo otros cielos, es el lugar absoluto, el pequeño fragmento de espacio con el cual, en el sentido estricto, hago cuerpo. (Foucault, 1966)

El cuerpo es el lugar en el que se realiza la experiencia de la vida. Nuestra condición humana es esencialmente corporal, afirma Le Breton (2010). Substraído el cuerpo de la experiencia, nada queda.

\section{El cuerpo socialmente construido}

El cuerpo se encuentra en la intersección contradictoria y paradójica de ser al mismo tiempo el objeto directo de la violencia y el lugar en que se puede realizar el empoderamiento. ¿A qué se debe este doble carácter antagónico? Diremos, primero, que el cuerpo rebasa ampliamente su condición puramente biológica. Todos los cuerpos son socialmente construidos y son resultado de su evolución histórica y sociológica (Pedraza, en el prólogo de Calero et al., 2015, p. 29). La sociedad utiliza muchos mecanismos persuasivos para intervenir en los cuerpos y moldearlos según sus intereses (por ejemplo, la observancia de un modelo canónico de belleza femenina o masculina, los regímenes alimentarios, los adornos corporales externos y los tatuajes sobre la piel, etc.). Los mismos individuos aplican estos mecanismos en sus propios cuerpos persuadidos de que, de esa manera, se ajustan correctamente al funcionamiento de la sociedad.

Pero otros mecanismos de intervención no son productos de la persuasión (que supone siempre la aceptación de las razones que justifican un proceder dado), sino de la imposición brutal y evidentemente de origen externo al cuerpo: el asesinato, la tortura, la desaparición, la vigilancia, la prisión, el desplazamiento forzado. Probablemente es por ello que Foucault (1977) consideraba que el cuerpo es el lugar en el cual se legitima 
la dominación que se ejerce sobre los sujetos. Para Foucault, la biopolítica consiste en el ejercicio del poder sobre los cuerpos para hacerlos socialmente funcionales (ideológica y productivamente) y por lo tanto, para dominarlos y gestionarlos ${ }^{3}$. De hecho, la educación que se le dio a la mujer en Colombia desde el siglo XIX (Pedraza, 2011) se ha mantenido hasta hoy como un ejercicio de poder. Este determina el lugar femenino en el espacio privado y piadoso del hogar, como amas de casa, madres, esposas, y donde adicionalmente, se sumó la belleza al conjunto de deberes de la feminidad impuesto por la variante biopolítica femenina.

En otro momento previo, Foucault se referió al mismo problema de esta forma:

Los métodos que permiten el control minucioso de las operaciones del cuerpo, que garantizan la sujeción constante de sus fuerzas y les imponen una relación de docilidad-utilidad, es lo que se puede llamar las disciplinas [...] la disciplina fabrica así, cuerpos sometidos y ejercitados, cuerpos dóciles. (Foucault, 1976, pp. 141-142)

Pedraza (2012) matiza esta idea de Foucault en un análisis centrado en la historia de Colombia:

Atribuyo el uso extendido de la noción de biopolítica en muchos análisis y estudios sociales, políticos y culturales recientes a los vínculos que esta categoría ha permitido tender entre la práctica de gobernar, el cuerpo como entidad histórica y política, la vida concebida como una responsabilidad estatal y el sentido del ejercicio del poder. Esto implica apreciar de qué manera la vida que puede ser gobernada habita en el cuerpo, y, más aun, se expresa en la entidad representada como "el cuerpo" en los últimos cinco siglos de la historia cultural y política del mundo occidental. (pp. 2-3)

Bajo el rigor del poder, los cuerpos en la sociedad son intervenidos. Pero a esta intervención, los sujetos en sociedad pueden oponer el ejercicio liberador del arte. Se trata, en palabras de Laura Quintana (2012),

$[\ldots]$ de unas "prácticas de libertad" que tienen que ver con la tarea de deshacerse de una identidad, que se le impone al sujeto como su verdad, y por ende, con una tarea de desidentificación o desindividualización, que permitiera que el sujeto pudiera relacionarse de otra forma consigo mismo y con la verdad, subjetivándose de otro modo. (p. 3)

Si el cometido de las intervenciones desde el poder busca la docilidad y la funcionalidad de los cuerpos, lo que busca su opuesto -el arte- es justamente lo contrario:

3 Es apenas coherente con el pensamiento de Foucault que los sistemas de poder hayan perfeccionado su control sobre los individuos acudiendo a medios panópticos de vigilancia (Foucault, 1977). Las nuevas tecnologías confirman dramáticamente este aserto de Foucault, bajo su mirada los sujetos sociales hemos perdido por completo nuestra privacidad; somos seres siempre vigilados. 
su liberación. Las prácticas artísticas propician la emancipación del ser humano ${ }^{4}$. Los cuerpos en situación de artisticidad se resisten a ser disciplinados; se convierten en territorio de luchas y resistencias desde la corporalidad misma. Subvierten el orden.

Ahora bien, no solo el arte provee esta vía de liberación, también puede ser provista por la ética. Foucault habló del sujeto ético como aquel que pretende "hacerse a sí mismo", que reflexiona sobre su existencia y toma la decisión de transformar su vida. Los cuerpos en el arte serían entonces objeto de lo que Foucault denominó "las prácticas de sí" o "técnicas de sí", que caracterizó como:

[... las prácticas sensatas y voluntarias por las que los hombres no sólo [sic] se fijan reglas de conducta, sino que buscan transformarse a sí mismos, modificarse en su ser singular y hacer de su vida una obra que presenta ciertos valores estéticos y responde a ciertos criterios de estilo. (Foucault, 1984, pp. 13-14)

Es, en términos no ya de Foucault sino de la paz imperfecta, el empoderamiento personal o stricto sensu, el empoderamiento pacifista: se generan prácticas corporales que buscan alcanzar la autonomía y crear una subjetividad propia.

Tamayo y Navarro (2017) introducen el concepto de ciudadanías comunicativas. Con ello, se refieren a una "acción política no convencional que expresan los públicos subalternos mediante libres selecciones simbólicas y afectivas que se centran en la estructuración de nuevas formas de organización social" (p. 58). A través de estrategias de comunicación no convencionales (como la transcodificación), basadas en las emociones, subjetividades y afectos, las víctimas retoman su condición de ciudadanos y están de nuevo en capacidad de reclamar por sus derechos.

\section{El producto artístico: parte y resultado del proceso}

El duelo es el resultado de un proceso durante el cual el cuerpo ha estado involucrado de principio a fin, y como consecuencia, el producto artístico que finalmente aparece tras el proceso de transcodificación es parte y resultado del proceso. La víctima debe participar en la elaboración de la obra pues, de acuerdo con el empoderamiento pacifista, debe asumir la dirección de su vida.

Plantear que el producto artístico es parte y resultado de una investigación inscrita en un proceso de paz y en la teoría de la paz imperfecta requiere desarrollo, ya que es clave para entender el procedimiento metodológico seguido en nuestras experiencias. Lo que se propone desde la investigación para la paz es romper los esquemas y paradigmas éticos preestablecidos para hacer la paz. Desaprender de lo En un artículo todavía inédito llamamos "ideologizados" a los cuerpos formados por la biopolítica (puesto que son formateados
por ella) y "trascendidos" (a través del arte) a los que desacatan las imposiciones de lo ideológico y se acogen al arte. 
andado, desaprender las guerras, violencias y exclusiones para aprender a hacer las paces, como dice Martínez (2000, p. 51). En otros términos, deconstruirse para volver a construirse. Hacer la paz comprende pues,

[...] la incorporación de una perspectiva abierta de los conflictos, la coexistencia de diversos proyectos e intereses en relación con el desarrollo de las capacidades y potencialidades o satisfacción de capacidades, el papel de las mediaciones, la paz negativa, positiva o imperfecta, la búsqueda de equilibrios dinámicos, el poder de los actores que defienden la paz o la deconstrucción de la violencia, y todo ello en el marco de la complejidad. (Jiménez y Muñoz, 2012, p. 8)

Para corresponder a estas nuevas lógicas, conviene proponer un giro epistemológico que busque reconocer y recuperar el papel central de la paz en las dinámicas artísticas. Hemos partido en nuestras experiencias no del conflicto para representarlo en el arte (como se ha procedido habitualmente), sino del arte para ir hacia la paz. En esto consiste el giro: no reaccionar al conflicto sino generar una acción, un producto artístico. En lugar de seguir una vía reactiva, se elige una propositiva.

Henk Borgdorff, del Amsterdam School of Arts, nutre el debate acerca de la producción artística y su relación con la investigación y la producción de sentido. La pregunta fundamental que se plantea Borgdorff (2010) es sobre el estatus y la naturaleza de la investigación en las artes plásticas y las artes escénicas y su relación con la práctica artística. ¿Puede valer la práctica de arte como investigación? Borgdorff propone tres formas de investigación artística. Primera, la investigación sobre el arte, que busca extraer conclusiones confiables sobre la práctica artística con una distancia teórica. Segunda, la investigación para el arte, entendida como los procesos en que el arte es el objetivo, más que el objeto de los procesos investigativos. En este caso la investigación estaría al servicio del arte. Por último, la investigación en el arte, que trata de un tipo de producción hecha desde la práctica misma, que no asume una separación entre sujeto y objeto, que no contempla distancia entre la práctica artística y el investigador. Para Borgdorff, esta última categoría defiende que la producción artística es en sí misma una parte fundamental del proceso de investigación, y la obra de arte es en parte, el resultado de ella. No existe separación fundamental alguna entre teoría y práctica en las artes. La práctica artística se puede calificar como investigación -aseguró Borgdorff (s. f.)- cuando su propósito es ampliar nuestro conocimiento y entendimiento a través de una práctica original. Para Borgdorff, el conocimiento artístico ya viene incorporado desde el proceso de creación de la obra, como en las prácticas artísticas y en las obras mismas. Este conocimiento expande los horizontes del mundo existente, les da nueva forma a través de expresiones táctiles, auditivas y visuales, estéticas, expresivas y emotivas. De esta manera, la obra, el proceso creativo y el contexto de significación son todos parte constituyente de la investigación para el arte. 


\section{Metodología}

Diversas son las vías a través de las cuales los miembros de una sociedad pueden alcanzar la paz tras los acuerdos que buscan la finalización de un conflicto social violento. La más recurrente es la política, pero esta resulta insuficiente per se puesto que sus decisiones requieren acompañamiento de otras pertenecientes a diferentes campos de lo social (jurídico, económico, laboral, legislativo, etc.). En la implementación de estos procesos de paz se trataría más bien de aplicar un haz complejo de recursos de naturaleza plural. Las experiencias homólogas adelantadas en Sudáfrica, Irlanda del norte y Argentina así lo confirman ${ }^{5}$.

En este trabajo se propone otra vía, menos explorada, quizás menos ortodoxa, surgida de la teoría de la paz imperfecta y concebida como consecuencia de un proceso establecido con criterios de la Comunicación. Esta idea es coherente con Galaz y Guarderas (2017), para quienes "[l]os procesos de intervención con mujeres víctimas surgen en diversas matrices semiótico-materiales. Es decir, complejas relaciones entre discursos y prácticas que configuran una manera de comprender el problema, los sujetos de la intervención y unas relaciones en esas prácticas" (p. 4).

Los puntos de partida y de anclaje de la formulación y de la materialización de esta propuesta se encuentran, como se ha dicho, en dos investigaciones adelantadas por la autora del presente artículo. En el contexto de la primera de ellas (cf. * p. 1) se adelantaron talleres durante 40 semanas (uno por semana) con mujeres originarias de la región Pacífico de Colombia, víctimas de la violencia política del país y desplazadas a un barrio marginal de la ciudad de Cali, mujeres en su mayoría afrodescendientes. Tras un proceso de acercamiento progresivo diseñado desde la Comunicación Social, a lo largo de las semanas estas mujeres contaron colectivamente con diversos recursos expresivos (narración oral, dibujos, improvisaciones, danzas regionales, preparación de platos propios de su cultura culinaria), sus duras experiencias personales (que en todos los casos hicieron de ellas mujeres desplazadas que habían perdido esposos, tierras, familiares, bienes), experiencias convertidas por la autora de este artículo en un relato literario dotado de una cohesión estética unitaria. Este relato sirvió de base para la creación de una coreografía de danza contemporánea en la que intervinieron las mujeres, no solo aportando el material básico del relato sino también como creadoras y bailarinas. En otros términos, estas mujeres narraron sus propias experiencias de la guerra, crearon un lenguaje intersemiótico que tradujo como danza y elementos coreográficos un relato hecho a partir de sus propias vivencias al danzar y ejecutar la coreografía en el escenario ${ }^{6}$. En rigor, todo el proceso consistió en un ejercicio de transcodificación que se puede calificar legítimamente como "artístico" en la medida en que se tradujo un producto artístico -el relato literario-en otro igualmente artístico -una

Para el caso de África del Sur ver Hilb, Salazar y Martin (2014).

6 Ver el producto artístico final en Toro Calonje (2017). 
obra de danza contemporánea-. Señalemos de paso: la transcodificación artística no es solo el producto final, es el proceso entero, desde su origen hasta su terminación.

La segunda de las investigaciones (Cf. ${ }^{*}$ p. 1) se adelantó con un grupo de estudiantes de la Universidad del Valle que por parte de esta institución reciben un tratamiento académico particular, dado que han pasado por circunstancias de violencia en su vida y han estudiado en instituciones precarias o precarizadas por el conflicto. Su situación de desventaja social frente a los que ingresan bajo parámetros normales es evidente; son víctimas. Con Guglielmucci (2017) coincidimos en que la condición de víctima es un constructo social que debe pasar por el reconocimiento social, pero también por una apropiación personal:

La apropiación por parte de una persona de la condición de víctima, ya sea para presentarse o identificarse, está ligada a los mundos de sentido, a sus colectivos de pertenencia previos y actuales, a sus expectativas a futuro y a los perjuicios o beneficios que puede acarrear una clasificación o un encasillamiento de este tipo en un campo de acción dado. (Guglielmucci, 2017, p. 88)

Seis mujeres estudiantes participaron en la experiencia de la investigación, seleccionadas por realizar actividades artísticas y porque voluntariamente aceptaron su adscripción: bailarinas, cantantes, instrumentistas, poetas. Las participantes ${ }^{8}$ intervinieron en los talleres y narraron en grupo e individualmente sus experiencias violentas (objeto de una reflexión común), de igual manera leyeron una obra artística reconocida con el fin de producir una versión personal transcodificada escrita en el lenguaje practicado por cada una: danza, canto, instrumento de cuerdas, poesía9. Las obras transcodificadas fueron: La niña de la columna de Ricardo Acevedo, La vendedora de cartuchos de Diego Rivera, La columna rota, de Frida Kahlo, una fotografía de Jesús Abad Colorado (sin nombre), La violencia de Alejandro Obregón, Hijas del agua de Ruvén Afanador y Ana González, El cristo crucificado de Diego Velázquez y Tales of the Arabian nights de Marc Chagall.

Los valores reconocidos a la obra original y el influjo del proceso en sus visiones sociales y personales provocaron un cambio de percepción sobre su propia situación individual, expresado en sus opiniones y en las obras producidas (ver el acápite de resultados).

$7 \quad$ En nuestras investigaciones distinguimos entre la víctima directa, primera -el asesinado o el desaparecido-, de la víctima indirecta -el familiar del fallecido o del desaparecido-, pero ambas son víctimas.

$8 \quad$ Pertenecen al grupo especial (llamado ASES, "estudiantes en condiciones de excepción" por estar en desventaja social debido a problemas políticos del país. Bajo la perspectiva de la teoría de la paz imperfecta, estas estudiantes se pueden considerar plenamente como víctimas de la guerra, mismo título de los asesinados, desaparecidos, desplazados, saqueados, deudos.

9 Estamos utilizando el término escribir en el sentido que le da la semiología: se escribe no solo lo verbal sino también cualquier sistema de significación. Así, pues, se escribe también con el cuerpo, la vestimenta, el mobiliario, etc. (Cf. Barthes, 1990, sobre todo el capítulo 2, "Dominios"). 
Como la metodología se inspira en la idea de que las víctimas de la violencia adquieren la capacidad de negociar la paz solo en la medida en que han hecho consciencia de su situación gracias a mecanismos de resiliencia y de empoderamiento personal, para alcanzar entonces los fines propuestos en los objetivos de este trabajo se contactaron víctimas de violencia política para adelantar con ellas los talleres de transdiscursividad.

Se recurrió a la transcodificación artística porque en la teoría que sustenta la investigación se postula que el arte es una de las herramientas más efectivas en la búsqueda del empoderamiento de las víctimas. El método crea las condiciones para vencer la resistencia a hacer públicas las historias dolorosas de las víctimas. Que sea un taller hecho por las mujeres implica que su orientación temática haya dependido de ellas: no hay decisiones impuestas sino propuestas en el desarrollo del taller, emanadas de él y asumidas libremente. Que el taller haya sido de transdiscursividad artística obliga a pensar los pasos metodológicos en función de los mecanismos de producción de los objetos artísticos.

En ambos procesos, las historias personales de las víctimas ligadas a la violencia se convirtieron en relatos orales. En el primero, esas historias se convirtieron en un relato literario que sirvió de base a una coreografía creada e interpretada por las participantes (dicho de otra manera, la historia de cada una, mediada por el relato, terminó por convertirse en una obra artística colectiva: la coreografía de danza: un claro ejemplo de transdiscursividad, pues un lenguaje específico -el relato- se transformó en un lenguaje de otra naturaleza -la danza-). En el segundo, las mujeres participantes confrontaron esa historia personal a obras artísticas consagradas y produjeron, en otro ejemplo de transdiscursividad, obras en otros sistemas semióticos: la pintura se convirtió en danza, poesía, música, canto.

Las etapas de desarrollo de la fase creativa pasan por vaivenes inherentes a la metodología de creación (indeterminación, incertidumbre, tanteos, desconocimiento del final del camino al que se llegará), conjurados en la medida en que las mujeres fueron adquiriendo consciencia de su cuerpo. En todos los casos, el método pasó por la consciencia del cuerpo, pues una obra artística solo existe a través del cuerpo del artista.

La finalidad de este método es crear -a través de la transcodificación- en las mujeres participantes una nueva consciencia de su situación con respecto a su pasado, con base en la cual se puedan empoderar y asumir su historia a través de nuevas narrativas. La incidencia de los mecanismos de resiliencia auspiciados por el taller es fundamental puesto que el cuerpo, gracias a ese fenómeno psíquico, activado por la metodología del taller, va recuperando la estabilidad perdida. Una víctima solo se 
logra recuperar plenamente (hacer las paces) en la medida en que adquiere consciencia plena de su condición.

El desarrollo práctico de los talleres, al apoyarse en los principios de la teoría de la paz imperfecta y de la investigación para la paz, exige la revisión pormenorizada de textos publicados en torno al tema, se abordaron principalmente aquellos producidos por investigadores de la Universidad de Granada, España, quienes aproximaron el asunto de la paz como un problema fundamental en las circunstancias actuales de la sociedad en general.

\section{Resultados}

En términos de la teoría de la paz imperfecta, en los dos grupos de mujeres, aparte del relato literario y la coreografía de la primera investigación y de los productos artísticos de la segunda, se dio un proceso de empoderamiento gracias al cual elaboraron mejor su duelo personal y alcanzaron de esta manera herramientas para asumir su vida desgarrada. En otras palabras, asumieron su pasado para proyectarse hacia el futuro. Para la teoría de la paz imperfecta, lograr que las víctimas se encuentren en condiciones de acceder a la paz requiere que ellas adquieran consciencia de su situación. En la búsqueda de ese estado, realizar el duelo (justamente bloqueado por la inconsciencia) es una estrategia capital, pues solo a partir de allí la víctima se puede empoderar y encarar su vida futura. La transcodificación artística facilita el desarrollo de ese proceso en las víctimas, no solo en la medida en que su avance permite la confrontación con su pasado, sino que también les permite asumir su presente.

En los talleres, todas estas mujeres desarrollaron su propia propuesta plástica mediante el ejercicio de transcodificación artística aquí reseñado. Constituyó un proceso de memoria, reescritura de su historia, reapropiación de los acontecimientos dolorosos de su pasado en busca de mayor conciencia de sí; un proceso cargado de emoción, creatividad, arte, que las ha llevado a una movilización personal. Así las cosas, de las declaraciones dadas por ellas - de las cuales citamos a continuación algunos fragmentos extraídos de los encuentros- se infiere:

El proyecto me ayudó a encontrar cosas que no conocía de mí. Nunca había compuesto una canción. Mucho menos desde el dolor. Y eso disparó algo, abrirme los ojos a lo que uno puede hacer con lo que está aprendiendo, lo que sabe y lo que puede llegar a transformar. Podría decir que dentro de la universidad ha sido el proyecto que me ha abierto los ojos a mi relación con los otros. (comunicación personal, octubre 2018)

Ha sido un proceso de construcción de paz, pero con nosotras mismas. Muchas hemos salido de nuestros lugares de donde vivimos. Más que sanar con agentes externos, ha sido encontrar esa paz interiormente. Ha sido muy 
gratificante. En este proceso hemos caminado todas como una sola. Ha sido maravilloso porque nos ha permitido adentrarnos más en una forma de construcción social y poder transmitirlo a una sociedad. (comunicación personal, octubre 2018)

Me di cuenta que no era tan fácil componer salsa. Siempre he compuesto baladas, pero el género que más me gustaba, no. Y cambió en mi vida que ya puedo seguir componiendo mis propias canciones en la versión salsera. Mi sensibilidad es más amplia, mi capacidad de perdón también. Removió algo, me hizo caer en cuenta de un talento que no sabía que tenía. (comunicación personal, octubre 2018)

Me ha ayudado a escribir canciones, nunca lo había intentado. Fue una experiencia muy linda y enriquecedora. Pude desahogarme, compartir las demás historias de las otras chicas. Fue muy bello... bailamos, cantamos, lloramos, contamos nuestras historias. Después de todo lo que se vivió, no podemos seguir aferrados a ese dolor, a todo eso que pasó, sino que también nos sirve para sacar algo maravilloso. Algo que fue doloroso, hacerlo maravilloso, hermoso. (comunicación personal, octubre 2018)

Este proceso lo ayuda a nivel de todo, nos hace cambiar, incluso la percepción de nuestras historias personales, el sentir, no ser tan indiferentes. Volverse un poco más crítico, más observador. La obra me permitió sanar heridas interiores. Pero, al tratar de transmitirlas a otras personas, me permite estar más tranquila con lo que soy. Y sentirme orgullosa de que lo que pasó, es importante en mi vida. (comunicación personal, octubre 2018)

Antes no era consciente de que pertenecía a una comunidad y de que soy importante. Es como volver a re-escribirnos. Para mí toda la vida ha sido muy importante la poesía, los cuentos, sentarnos con los abuelos a contar historias... No sé por qué la abandoné, porque a mí me encanta. Este proyecto me hizo recordar muchas vivencias de mi familia que son mucho de contar historias, de la oralidad. Me he sentido muy bien en el proyecto, siento que me ha aportado. Me hizo recordar mis raíces, todo lo vivido dolorosamente y recordarlo con tranquilidad. (comunicación personal, octubre 2018)

Con respecto a la experiencia con las mujeres desplazadas del Pacífico, el video de la autora referenciado al final (Toro Calonje, 2017) aporta respuestas semejantes.

\section{Discusión y conclusiones}

¿Por qué elegir el arte como herramienta de este ejercicio de transcodificación y no otro recurso? Bastaría con la siguiente razón: el arte es quizás, al lado de la lengua, la actividad de mayor capacidad de simbolización. Cuando las mujeres del Pacífico, desgarradas por la intervención de la violencia, transforman su propia experiencia dolorosa en una danza, están expresando de manera simbólica el triunfo de la vida sobre la muerte. La danza es apertura, opuesta a la muerte, que es cierre y fin. 
Danzar es creer que hay un futuro e inscribirse en esa perspectiva, esta creencia se opone al estado estático en el que quedan estancados y absortos los muertos y los familiares que no pueden elaborar el duelo. De esa manera simbólica, los familiares víctimas escapan al estado de postración y perplejidad en que el ejercicio de la violencia contra ellas las ha dejado. Se empoderan y se asumen en su nueva vida a través de elementos simbólicos artísticos (como son la danza, una pieza musical, una canción...).

Los muertos del Guernica no son, claro, los muertos de los bombardeos contra esa población española: son su representación simbólica. Los deudos de esos muertos han visto en esa pintura a sus propios muertos simbolizados y quienes escuchamos la referencia al bombardeo vemos en esos muertos la barbarie y la lucha que la sociedad libra contra ella simbolizados. La lucha encarnizada que Antígona libra contra Creonte para recobrar el cadáver de Polinices, su hermano, muerto en el campo de batalla y yaciente a la intemperie a merced de los buitres y los lobos, y honrarle con funerales dignos y darle sepultura, resuena hoy en las voces de los familiares de los ochenta mil desaparecidos que en Colombia quieren encontrar a sus seres queridos para enterrarlos y así hacer el duelo.

Las mujeres colombianas víctimas de la desaparición de sus familiares son Antígonas contemporáneas. Y Antígona, de Sófocles es un paradigma sobre cómo el arte interviene en la elaboración del dolor de los sobrevivientes (otra forma de llamar al duelo) y en la reconstitución de la identidad de las víctimas. Una obra de arte tiene la capacidad de devolver la visibilidad a las víctimas y restituirles su condición humana y transmutar su ausencia en un nuevo cuerpo (véase por ejemplo, las intervenciones de la artista Doris Salcedo en la Plaza de Bolívar de Bogotá).

Hemos propuesto el abordaje de dos experiencias con víctimas del conflicto colombiano basadas en preceptos de la Comunicación Social y de la investigación para la paz. Todos los parámetros para la realización de las experiencias con las mujeres en ambas investigaciones se trazaron con criterios derivados de la Comunicación Social. Aproximaciones desde otros campos (Sociología, Historia, Antropología, Estudios de género) hubiesen sido posibles, acudir a la Comunicación Social ha sido una opción metodológica libre.

El proceso de transcodificación no se limita al producto final: cubre desde los inicios de los encuentros con el comunicador social hasta la difusión final del producto: acercamientos, persuasión, vacilaciones, reticencias, vencimiento de resistencias, son parte fundamental del camino de construcción artística y de reconstrucción personal.

La sociedad ejerce control sobre sus individuos de múltiples maneras, que buscan todos la conformidad normativa. El arte permite a estos mismos individuos trazar un rumbo a sus vidas por fuera de las imposiciones de la sociedad. En tales casos, es el arte el que traza el derrotero social. El arte puede ser una liberación. 
El movimiento hacia el duelo es considerado en sí mismo una movilización social: la víctima transforma la consciencia sobre su propia experiencia, se empodera de su condición y da un salto perceptivo. La nueva sensibilidad en torno a su condición humana y social heredada se va formando a lo largo del proceso.

En la búsqueda de un método que induzca a la movilización social, acudir a ejercicios de transcodificación artística puede ser útil en la medida en que el procedimiento incide en la modificación de la consciencia del sujeto ejecutante así como, potencialmente, de los espectadores que consuman el producto transmutado.

Como concepto clave en la implementación de los mecanismos de transcodificación artística proponemos el empoderamiento pacifista: a través suyo se produce el engranaje operativo entre la teoría de la paz imperfecta y los procesos de comunicación que apelan a la transcodificación artística como recurso para alcanzar la paz.

\section{Referencias}

Barthes, R. (1990). La aventura semiológica. Paidós.

Borgdorff, H. (2010). El debate sobre la investigación en las artes. Cairon: Revista de ciencias de la danza, 13, 25-46. https://bit.ly/2FV8vuH

Borgdorff, H. (s. f.). The Conflict of the Faculties: on Theory, Practice and Research in Professional Arts Academies. https://bit.ly/2ZKK8UQ

Calero, S., Rivera Gómez, C. C. y Restrepo Hoyos, P. (eds.) (2015). Cuerpo y comunicación. Universidad Autónoma de Occidente.

Cyrulnik, B., Manciaux, M., Sánchez, E., Colmenares, M. E., Olaya, M. M., Balegno, L. y Cano, F. (2006). La Resiliencia: Desvictimizar la víctima (2. ${ }^{a}$ ed.). Rafue.

Derrida, J. (2012). Pardonner: L'impardonnable et l'imprescriptible. Éditions Galilée.

Foucault, M. (1966). "Le corps utopique". Conferencia radiofónica transmitida el 7 de diciembre de 1966 por France-Culture. https://www.youtube.com/watch?v=L8iyy0m3P38 (parte1); https:// www.youtube.com/watch?v=OeOmXEagOSM (parte 2).

Foucault, M. (1975/1976). Vigilar y castigar. Siglo XXI Editores.

Foucault, M. (1977). Historia de la sexualidad: Vol. 1: La voluntad de saber. Siglo XXI Editores.

Foucault, M. (1984). Historia de la sexualidad: Vol. 2: El uso de los placeres. Siglo XXI Editores.

Franco, P. y López, A. M. (2011). Una mirada a las raíces de la comunicación para el desarrollo. (entrevista con Luis Ramiro Beltrán Salmón). Revista Signo y Pensamiento, 30(58), 170-177. https://doi.org/10.11144/Javeriana.syp30-58.mrcp

Galaz, C. y Guarderas, P. (2017). La intervención psicosocial y la construcción de las "mujeres víctimas": una aproximación desde las experiencias de Quito (Ecuador) y Santiago (Chile). Revista de Estudios Sociales, 59, 68-82. https://journals.openedition.org/revestudsoc/531 
Galtung, J. (1985). Sobre la paz. Fontamara.

Guglielmucci, A. (2017). El concepto de víctima en el campo de los derechos humanos: una reflexión crítica a partir de su aplicación en Argentina y Colombia. Revista de Estudios Sociales, 59, 83-97. https://doi.org/10.7440/res59.2017.07

Harto de Vera, F. (2016, 16 de marzo). Investigación para la paz y la transformación pacífica de conflictos [conferencia]. Universidad del Valle, Cali, Colombia.

Haye, A., Herraz, P., Cáceres, E., Morales, R., Torres-Sahli, M. y Villarroel, N. (2018). Tiempo y memoria: sobre la mediación narrativa de la subjetividad histórica. Revista de Estudios Sociales, 65, 22-35. https://doi.org/10.7440/res65.2018.03

Hilb, C., Salazar, P. J. y Martin, L. G, (eds.). (2014). Lesa humanidad: Argentina y Suráfrica: Reflexiones después del mal. Katz Editores.

Jakobson, R. (1984). En torno a los aspectos lingüísticos de la traducción. En Ensayos de lingüística general (pp. 67-77). Ariel.

Jiménez, J. M. y Muñoz, F. (eds.). (2012). La paz, partera de la historia. Universidad de Granada.

Le Breton, D. (2010). Cuerpo sensible. Ediciones Metales Pesados.

Lemaitre, J. y Restrepo, E. (2019). Law and Violence in the Colombian Post-Conflict: StateMaking in the Wake of the Peace Agreement. Revista de Estudios Sociales, 67, 2 16. https://doi. org/10.7440/res67.2019.01

Martín-Barbero, J. (201 1). Los oficios del comunicador. Signo y Pensamiento, 30(59), 18-40. https:// doi.org/10.11144/Javeriana.syp31-59.ofco

Martínez Guzmán, V. (2000). Saber hacer las paces: epistemología de los estudios para la Paz. Revista Convergencia, 7(23), 49-96. https://convergencia.uaemex.mx/article/view/1814

Merleau-Ponty, M. (2013). Phenomenology of perception. (D. A. Landes, trad.). Routledge.

Muñoz, F. A. (ed.). (2001). La paz imperfecta. Universidad de Granada.

Muñoz, F. A. (2014, junio 10). El campo transdisciplinar para la paz [conferencia]. Universidad del Valle, Cali, Colombia.

Muñoz, F. A. y Molina Rueda, B. (2010). Una paz compleja, conflictiva e imperfecta. Universidad de Granada.

Muñoz, F. A., Herrera, J., Molina, B. y Sánchez, S. (2005). Investigación para la paz y los Derechos Humanos en Andalucía. Universidad de Granada.

Pedraza, Z. (201 1). La "educación de las mujeres": el avance de las formas modernas de feminidad en Colombia. Revista de Estudios Sociales, 41, 72-83. https://doi.org/10.7440/res41.2011.06

Pedraza, Z. (2012). La disposición del gobierno de la vida: acercamiento a la práctica biopolítica en Colombia. Revista de Estudios Sociales, 43, 94-107. https://doi.org/10.7440/res43.2012.08

Pérez G., (2009). Ética y comunicación en la perspectiva de los derechos humanos. Signo y Pensamiento, 28(55), 50-65. https://revistas.javeriana.edu.co/index.php/signoypensamiento/ article/view/3742 
Quintana, L. (2012). Singularización política (Arendt) o subjetivación ética (Foucault): dos formas de interrupción frente a la administración de la vida. Revista de Estudios Sociales, 43, 50-62. https://doi.org/10.7440/res43.2012.05

Sófocles (2009). Antígona. Editorial Debolsillo.

Tamayo Gómez, C. y Navarro Bohórquez, D. (2017). Después de la guerra: otra Medellín: ciudadanías comunicativas, apropiación urbana y resignificación de espacios públicos en clave de memoria y posconflicto. Signo y Pensamiento, 36(70), 54-73. https://doi.org/10.11144/ Javeriana.syp36-70.dgmc

Toro Calonje, A. (dir. y guionista). (2017). Girasoles. Obra de danza contempóranea interpretada por mujeres del Pacífico colombiano, víctimas de la violencia. https://www.youtube.com/watch?v=Rr9YzZo78HA

Zuleta, E. (2000). Elogio de la dificultad. https://bit.ly/1 FpYkRo 